\title{
The proteolytic procaspase activation network: an in vitro analysis
}

\author{
M Van de Craen ${ }^{1,2}$, W Declercq ${ }^{1}$, I Van den brande ${ }^{1}$, W Fiers ${ }^{1}$ \\ and $P$ Vandenabeele ${ }^{\star, 1}$ \\ 1 Department of Molecular Biology, University of Gent and Flanders \\ Interuniversity Institute for Biotechnology, Gent, Belgium \\ 2 Current address: Devgen, Technologiepark 9, B-9052 Zwijnaarde, Belgium \\ * Corresponding author: P Vandenabeele, Department of Molecular Biology, \\ K.L. Ledeganckstraat 35, B-9000 Gent, Belgium. Fax: +32-9-264-53-48; \\ E-mail: peter.vandenabeele@dmb.rug.ac.be
}

Received 20.1.99; revised 20.7.99; accepted 19.8.99

Edited by M Hengartner

\begin{abstract}
In general, apoptotic stimuli lead to activation of caspases. Once activated, a caspase can induce intracellular signaling pathways involving proteolytic activation of other caspase family members. We report the in vitro processing of eight murine procaspases by their enzymatically active counterparts. Caspase-8 processed all procaspases examined. Caspase- 1 and -11 processed the effector caspases procaspase- 3 and -7 , and to a lesser extent procaspase- 6 . However, vice versa, none of the caspase-1-like procaspases was activated by the effector caspases. This suggests that the caspase-1 subfamily members either act upstream of the apoptosis effector caspases or else are part of a totally separate activation pathway. Procaspase-2 was maturated by caspase- 8 and -3 , and to a lesser extent by caspase- 7 , while the active caspase-2 did not process any of the procaspases examined, except its own precursor. Hence, caspase-2 might not be able to initiate a wide proteolytic signaling cascade. Additionally, cleavage data reveal not only proteolytic amplification between caspase- 3 and -8 , caspase- 6 and -3 , and caspase- 6 and -7 , but also positive feedback loops involving multiple activated caspases. Our results suggest the existence of a hierarchic proteolytic procaspase activation network, which would lead to a dramatic increase in multiple caspase activities once key caspases are activated. The proteolytic procaspase activation network might allow that different apoptotic stimuli result in specific cleavage of substrates responsible for typical processes at the cell membrane, the cytosol, the organelles, and the nucleus, which characterize a cell dying by apoptosis.
\end{abstract}

Keywords: apoptosis; caspase; cleavage; procaspase; proteolysis

Abbreviations: Ac-DEVD-amc, acetyl-Asp(OMe)-Glu(OMe)-ValAsp(OMe)-aminomethylcoumarin; Ac-YVAD-amc, acetyl-Tyr-ValAla-Asp-amino-methylcoumarin; afc, 7-amino-4-trifluoromethylcoumarin; amc, 7-amino-4-methylcoumarin; zVAD-afc, benzyloxycarbonyl-Val-Ala-Asp(OMe)-amino-trifluoromethylcoumarin

\section{Introduction}

Apoptosis is an evolutionary well-preserved process of cell death essential to ontogeny, homeostasis and cellular differentiation. ${ }^{1}$ A conserved family of cytoplasmic cysteinyl aspartate-specific proteinases, called caspases, are crucial in this physiological pathway to cell death. ${ }^{2,3}$ Based on amino acid homology these caspases can be subdivided in three families: the caspase-1 subfamily (caspase-1, -4/-11, -5, -12 and -13 ), the caspase-3 subfamily (caspase-3, -6, -7, -8 and -10 ) and the caspases related to caspase-2 (caspase-2, -9 , and -14). ${ }^{2,4-6}$ This comparison also shows that caspase-11/ Ich3 is most probably the murine homologue of human caspase-4/TX/Ich2/ICE rell ${ }^{4,7}$ The primary structure of the caspase zymogens (procaspases) consists of a prodomain followed by a large subdomain of $\sim 20 \mathrm{kDa}$ (p20) and a small subdomain of $\sim 10 \mathrm{kDa}(\mathrm{p} 10){ }^{2}$ Small linker peptides often separate the different subunits. Procaspase-3, -6, -7 and -14 have very small prodomains (up to $3 \mathrm{kDa}$ ), while the other procaspases contain longer prodomains (from 10 to $26 \mathrm{kDa}$ ). The caspase zymogens are believed to be enzymatically inactive or at most to have a very low enzymatic activity. ${ }^{8}$ Some caspase precursors require oligomerization of the large prodomain for activation. ${ }^{9-12}$

The maturation of procaspases involves cleavage after specific aspartic acid residues located between the different subdomains. So far, only three types of protease have been reported to perform this type of maturation: the caspases themselves, the serine proteinase granzyme $\mathrm{B}^{7,13-15}$ and cathepsins. ${ }^{16,17}$ Experimental evidence suggests that caspases might act in some form of proteolytic activation cascade. ${ }^{18-22}$ These proteolytic caspase activation cascades presumably constitute an intracellular mechanism for transmission of (death) signals. However, data reported so far on potential caspase proteolytic cascades are fragmentary and have not been obtained under comparable experimental conditions.

We cloned and purified nine different murine caspases. ${ }^{4,5,23}$ In this paper, we examined the mutual in vitro processing of eight of these (pro)caspases in order to provide a comprehensive understanding of the proteolytic signaling by procaspase activation cascades.

\section{Results}

\section{Bacterial expression and purification of eight murine caspases}

Previously, we reported the cloning of seven different murine caspases by family PCR. ${ }^{4}$ Additionally, we isolated murine caspase- $8 .{ }^{23}$ In order to obtain enzymatically active preparations, we expressed the caspases devoid of prodomains (p30 caspases) in Escherichia coli. The caspases were purified based on $\mathrm{a} \mathrm{His}_{6}$ tag interacting matrix. Bacterially expressed p30 caspases were processed with variable efficiency to the 
$\sim$ p20 and $\sim$ p10 subunits, characteristic of active caspases. To normalize for the amount of mature caspases, equal concentrations of $\sim$ p20 subunit of each caspase were used in all experiments. Incubation of the recombinant caspase preparations under conditions identical to these applied in cleavage experiments did not change the silver stain pattern of the caspase preparation, suggesting the absence of autoprocessing at the concentrations tested (Figure 1). The caspase concentration in this experiment $(2 \mu \mathrm{g} / 30 \mu \mathrm{l})$ exceeded the concentration used in the procaspase cleavage assays $(60 \mathrm{ng} / 25 \mu \mathrm{l})$, a fortiori excluding autoprocessing in the latter experiment.

A number of oligopeptide substrates have been developed based on the recognition site in prototype substrates. Acetyl-Tyr-Val-Ala-Asp-aminomethylcoumarin (Ac-YVAD-amc) and benzyloxycarbonyl-Val-Ala-Asp(OMe)aminotrifluoromethylcoumarin (zVAD-afc) are derived from one of the two caspase-1 cleavage sites in prointerleukin$1 \beta$ (YVHD), while acetyl-Asp(OMe)-Glu(OMe)-ValAsp(OMe)-aminomethylcoumarin (Ac-DEVD-amc) was based on the caspase-3 cleavage site in poly(ADP-ribose) polymerase. Fluorometric assays were performed to test the enzymatic activities of the purified caspases on these peptide caspase substrates. All caspase preparations, except caspase-12, scored positive on at least one of the three oligopeptide substrates (Table 1), which confirms their functionality. Since the concentrations of caspases had been normalized on the amount of p20, differences in specific enzymatic activities were most probably due to substrate specificity of the caspases.

\section{In vitro cleavage of procaspases by caspases}

On the basis of their biological function, the caspases tested can be classified in three groups: proinflammatory caspases (caspase-1, -11 and -12), receptor-associated caspases (caspase-2 and -8) and effector caspases (caspase-3, -6 and $-7) .{ }^{2435}$ S-Met-labeled in vitrotranscription/translation products of the murine cDNA clones coding for caspase precursors (procaspases) were used as substrates for purified recombinant caspases. In order to distinguish between prodomain and

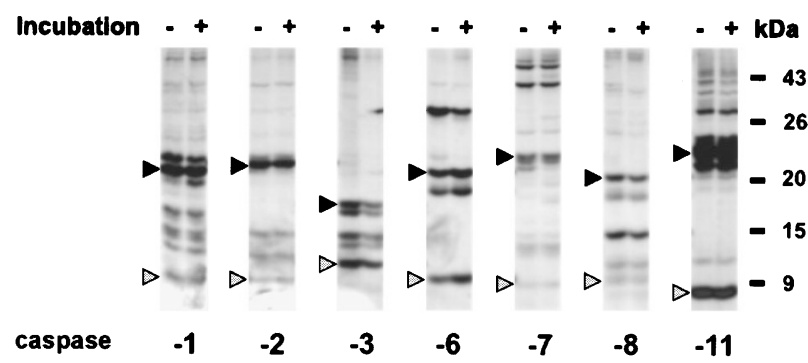

Figure 1 Incubation of recombinant caspase preparations. Caspases devoid of prodomain were expressed in $E$. coli and purified. All caspase preparations, except caspase-12 and -14 (data not shown), contain fragments indicative of mature caspase (arrowheads). In order to control further autoprocessing during incubation with substrate, the caspase preparations $(2 \mu \mathrm{g} / 30 \mu \mathrm{l})$ were incubated in reaction buffer for $1.5 \mathrm{~h}$ at $37^{\circ} \mathrm{C}$. The caspase preparations before and after incubation were analyzed by $15 \%$ SDS - PAGE ( $2 \mu \mathrm{g}$ per lane) and revealed by a modified silver stain protocol $^{43}$ p10 processing, both the precursor forms (Figures 2-4) and the p30 caspases were examined as substrates (data not shown). Since we were unable to show any enzymatic activity for caspase-12 in these assays (Table 1), caspase-12 experiments were not included. The in vitro proteolytic experiments were performed at an enzymatic concentration of $60 \mathrm{ng} \sim \mathrm{p} 20 / 25 \mu \mathrm{l}$, which corresponds to approximately $120 \mathrm{nM}$ of mature caspase. This concentration is in accordance with that of active caspase- 3 in cell lysates, viz. 100 nM. $^{25}$

\section{Cleavage of proinflammatory procaspases}

Procaspase- 1 was weakly processed between the $\sim$ p20 and $\sim$ p10 subunits by caspase- 1 itself and by caspase- 11 , as evidenced by the generation of 37/35-kDa bands (Figure 2A). On the other hand, caspase-8 efficiently cleaved procaspase1 (Figure 2A). The 35-kDa band is probably a result of further processing of the $37-\mathrm{kDa}$ form by removal of the 2-kDa spacer peptide present between the $\sim$ p20 and $\sim$ p10 subunits. The cleavage sites in procaspase-1 shown in Figure $2 \mathrm{~A}$ are based on literature data. ${ }^{8}$

Procaspase-11 was weakly processed by caspase-1, reflected by the appearance of a weak $37.5-\mathrm{kDa}$ band above a band formed as a result of internal initiation (Figure 2B). However, since p30 caspase-11 was not a substrate for caspase-1 (data not shown), this cleavage probably occurred at the prodomain level. As was the case for procaspase-1, procaspase-11 was most effectively cleaved by caspase-8, resulting in release of the $\sim$ p10 subunit. The exact cleavage sites responsible for human procaspase-4 or murine procaspase-11 processing have not yet been defined, but a similar cleavage pattern was also observed when human procaspase-4 was hydrolyzed by human caspase-8. ${ }^{20,26}$ Furthermore, Western blotting revealed that tissues of mice treated with lipopolysaccharide contained similar caspase-11 fragments. $^{27}$ Release of the $\sim$ p10 subunit presumably results in activation of procaspase-11, by analogy with activation of procaspase- 1 and $-4 .^{8,9}$

Caspase-3 and -7 processed procaspase-12 at the prodomain (Figure $2 \mathrm{C}$ ), since p30 caspase-12 showed no cleavage by caspase-3 or -7 under identical conditions (data not shown). This cleavage occurred presumably at the DEDD $_{94}$ site, which encompasses the DXXD consensus sequence for caspase-3-like enzymes. ${ }^{24}$ Although

Table 1 Caspase activity on peptide substrates

\begin{tabular}{lrcc}
\hline & Ac-DEVD-amc & Ac-YVAD-amc & zVAD-afc \\
\hline Caspase-1 & 11726 & 118300 & 38195 \\
Caspase-11 & 17969 & 7637 & 62039 \\
Caspase-12 & 0 & 0 & ND \\
Caspase-2 & 42000 & 0 & 0 \\
Caspase-8 & 911950 & 67610 & 91080 \\
Caspase-3 & 8004500 & 53000 & 23900 \\
Caspase-6 & 568180 & 357 & 4535 \\
Caspase-7 & 312800 & 8500 & ND \\
\hline
\end{tabular}

Specific enzymatic activities of recombinant caspases on peptide substrates are expressed in $\mathrm{U} / \mathrm{mg}$. Equal amounts of active caspase protein were added, based on the p20 subunit content of the preparation. One unit of caspase activity corresponds to the amount of caspase required to generate 1 pmole of free amc or afc/min at $30^{\circ} \mathrm{C}$ 
A

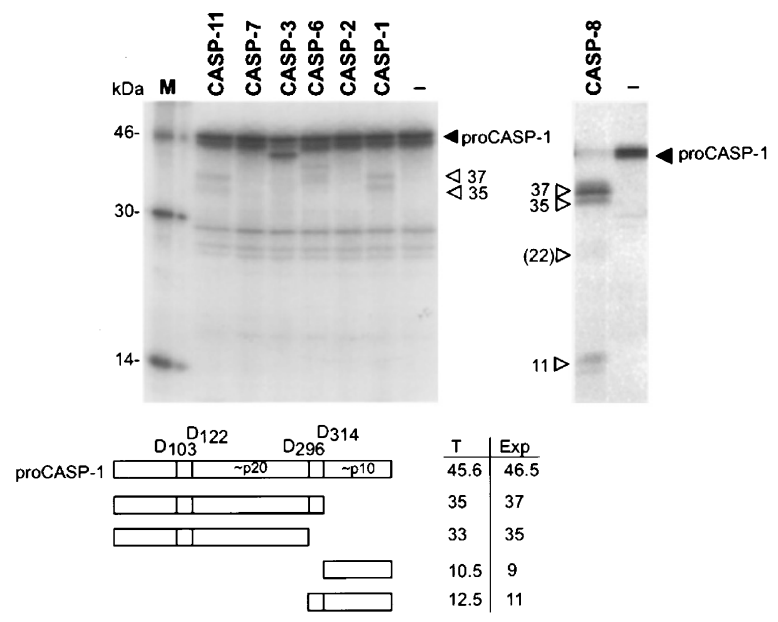

B

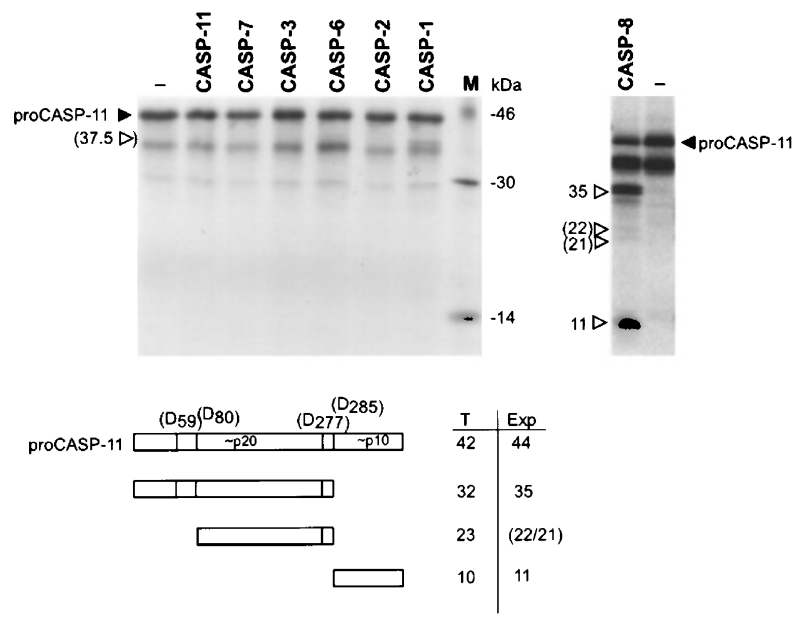

C
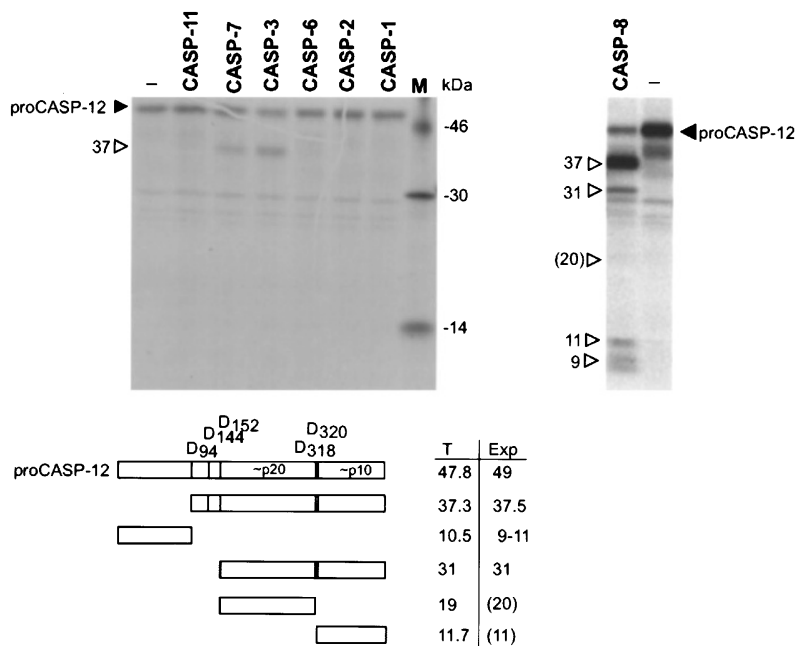

Figure 2 In vitro cleavage of proinflammatory procaspases by different caspases. ${ }^{35}$ S-labeled proinflammatory procaspases were incubated for $1.5 \mathrm{~h}$ at $37^{\circ} \mathrm{C}$ with recombinant caspases in caspase buffer, and then analyzed by caspase-8 generated additional cleavage products, it mainly cleaved at the prodomain of procaspase-12 (presumably $D_{144}$ and $D_{152}$ ), which does not result in activation of procaspase-12. This suggests that procaspase-12 might be activated by an alternative mechanism.

In general, it might be concluded that procaspase-1, -11 and -12 are, compared to other procaspases (see below), poor substrates for the caspases tested. One exception is caspase-8, which might represent an efficient apical initiation mechanism of activation of these proinflammatory caspases. However, involvement of other activation mechanisms for the processing of these proinflammatory caspases, such as autoproteolytic activation by homodimerization ${ }^{9-12}$ or other proteases, such as cathepsin $\mathrm{B}^{16,17}$ may be more likely. In this respect, the high transcriptional inducibility of caspase$1,{ }^{28}$ caspase-11 and caspase-12 should be noted (G Denecker, unpublished data). Nevertheless, it cannot be excluded that untested initiator caspases are involved in the activation of proinflammatory caspases.

\section{Cleavage of receptor-associated procaspases}

In addition to caspase-8, caspase-2 has also been reported to be recruited to an activated receptor complex, though the evidence is indirect. ${ }^{29}$ Caspase-8, caspase- 3 and, to a lesser extent, caspase-7 were able to process procaspase-2, as clear from the disappearance of the precursor form (Figure $3 \mathrm{~A})$. Additionally, procaspase-2 was processed between the $\sim$ p20 and $\sim$ p10 subunits (in decreasing order of activity) by caspase-2, $-6,-1$ and -11 (Figure $3 \mathrm{~A}$ ). The in vitro procaspase-2 cleavage fragments generated by caspase-8, -3 and -7 were also detected in HeLa or Jurkat cells stimulated to apoptosis by tumor necrosis factor or Fas, respectively; $D_{3 з 3}$ was mapped by mutagenesis to be the primary cleavage site of human procaspase-2. ${ }^{29}$ Indeed, most caspases appear to cleave procaspase-2 at position $D_{333}$, as witnessed by the generation of a $14-\mathrm{kDa}$ band. The heterogeneity of the caspase-2 bands around $37 \mathrm{kDa}$ was also noticed by Western blot analysis of human cell lysates and by in vitro cleavage of human procaspase-2 with caspase-1, -2 and $-3 .^{29,30}$ Interestingly, an additional weaker cleavage of procaspase-2 by caspase-2 between prodomain and $\sim$ p20 subunit has also been observed. ${ }^{30}$

The profile of procaspase- 8 cleavage was rather complex, but the molecular mass profile of the cleavage products from human procaspase- 8 after Fas stimulation, ${ }^{31}$ the assignment of the cleavage sites in human caspase$8,{ }^{20,32}$ as well as multiple sequence alignment of human and murine caspase $-8^{23}$ allow to identify the fragments generated. Generation of the $\sim$ p20 and $\sim$ p10 subunits indicative of fully mature caspase-8 was only clearly detectable in the case of treatment with caspase- 8 and -3 , as well as (though hardly detectable) with caspase- 6 .

15\% SDS-PAGE and autoradiography. Closed arrowheads, substrate (procaspase); open arrowheads, cleavage products. The smaller products are due to internal initiation in the in vitro translation reaction. ${ }^{7}$ Diagrams show the location of the presumed cleavage sites and the molecular mass of the theoretically expected (T) and experimentally obtained (Exp.) fragments. (A) Cleavage of procaspase-1; (B) cleavage of procaspase-11; (C) cleavage of procaspase-12 
The amount of $45-\mathrm{kDa}$ fragment generated, which represents the prodomain connected to the $\sim$ p20 subunit, indicated that caspase- 6 could efficiently process procaspase- 8 between the $\sim$ p20 and $\sim$ p10 subunits (Figure 3B). Also caspase-8 and -3 preferentially cleaved at the latter site. Recently, it has been demonstrated that oligomerization of procaspase-8 might initiate receptordependent activation of procaspase-8. ${ }^{12}$ Our results suggest that mainly caspase- 8 and -3 , but also caspase6 , might be implicated in the amplification of procaspase-8 activation, and might therefore mediate procaspase-8 activation independently of death domain recruitment.

\section{Cleavage of effector procaspases}

Procaspase-3 was fully converted to the active form, in decreasing order of activity, by caspase-6, -8, -11 and -3 , as can be deduced from the generation of $\sim$ p20 and

A

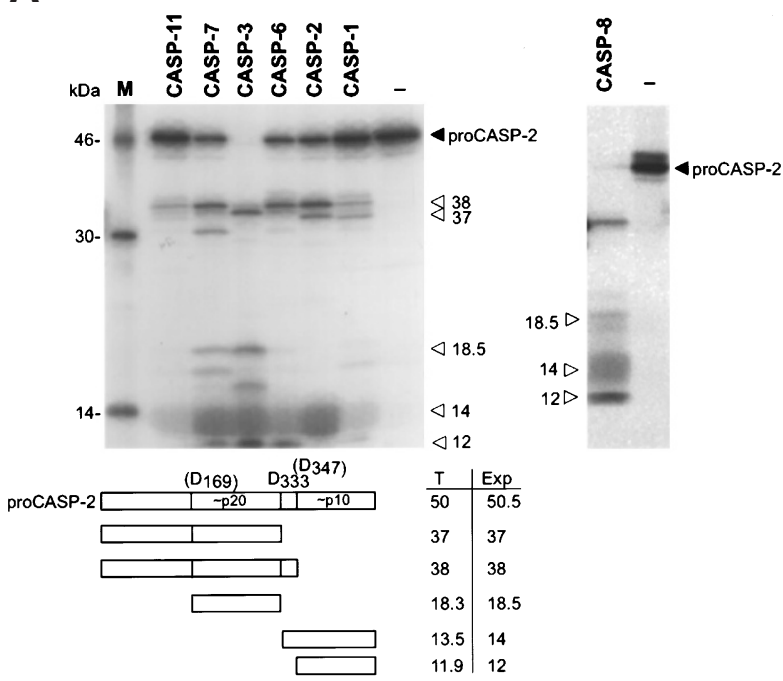

\section{B}
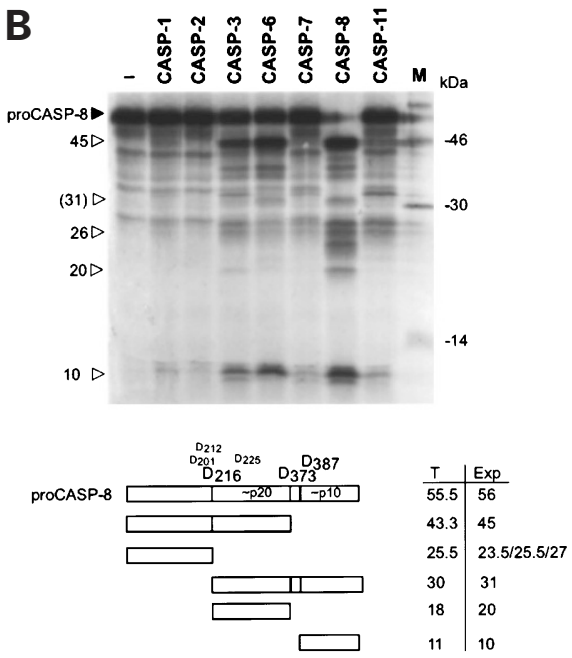

Figure 3 In vitro cleavage of receptor-associated procaspases- 8 and -2 by caspases. Incubation, analysis and autoradiography were performed as described in the legend to Figure 2, where the indications on the diagrams are also explained. (A) Cleavage of procaspase-2; (B) cleavage of procaspase-8 $\sim$ p10 fragments (Figure 4A). The caspase cleavage sites have been identified for human caspase $-3^{33}$ and are conserved in murine caspase- $3 .^{7}$ Caspase- 7 processed
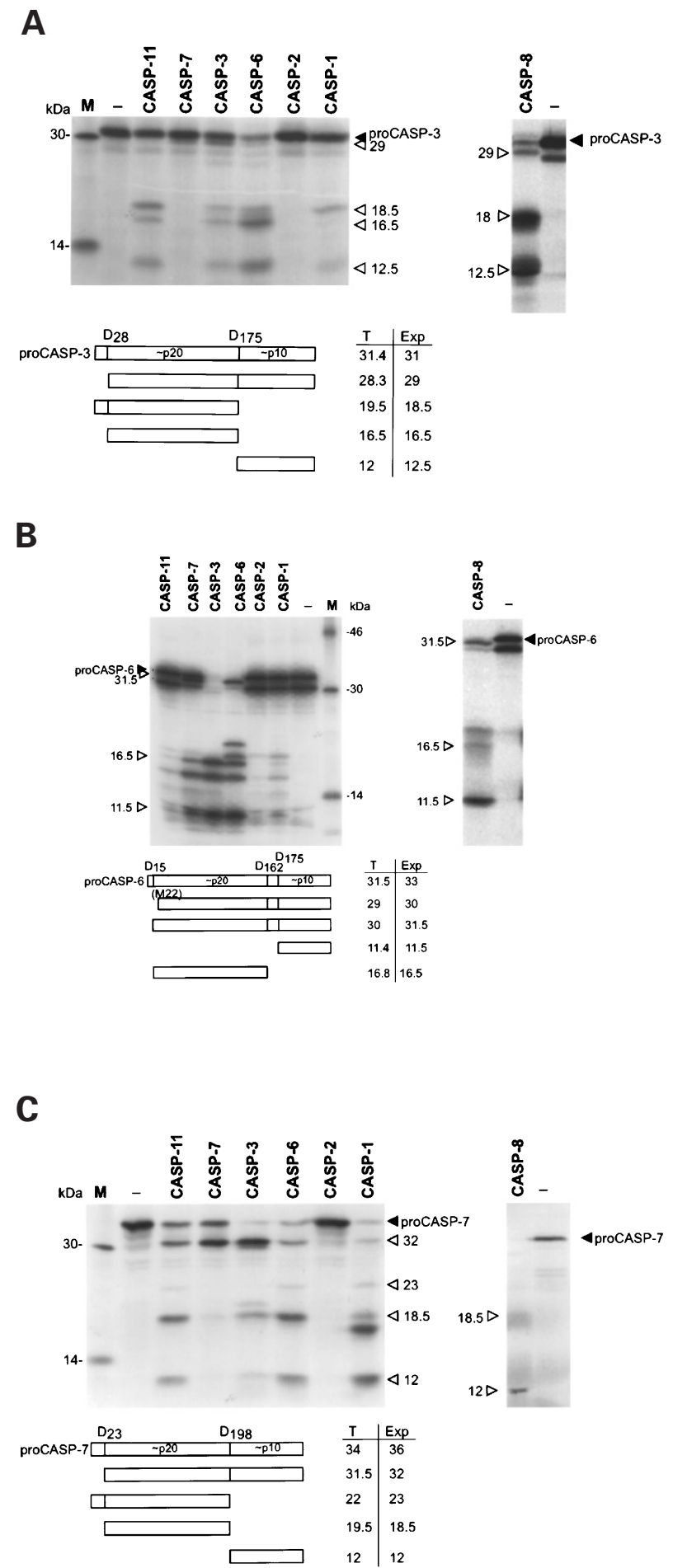

Figure 4 In vitro cleavage of effector procaspases by different caspases. Incubation, analysis and autoradiography were performed as described in the legend to Figure 2, where the indications on the diagrams are also explained. (A) Cleavage of procaspase-3; (B) cleavage of procaspase-6; (C) cleavage of procaspase-7 
procaspase- 3 weakly at the prodomain, as shown by the presence of a faint band just below the precursor form. The other potential cleavage sites were not recognized by caspase-7. Interestingly, caspase-1 cleaved procaspase-3 at the $\sim$ p10 domain, but the small prodomain was not removed from the $19-\mathrm{kDa}$ subunit as evidenced by the absence of a $16.5-\mathrm{kDa}$ fragment. Also this type of cleavage results in active caspase- $3 .^{34}$

Many caspases could process procaspase-6: caspase-3, caspase-6, caspase- 8 and, to a lesser extent, caspase-7, as shown by the generation of $\sim$ p20 and $\sim$ p10 fragments (Figure 4B). It should be noted, however, that these results contradict those of Kang et $a l^{35}$ who show that neither caspase- 8 nor caspase- 3 are able to process procaspase- 6 during coexpression in Saccharomyces cerevisiae. Caspase- 1 and caspase-11 induced only a minor maturation of procaspase- 6 . The cleavage sites of human caspase- 6 have been determined. ${ }^{36}$ These sites are conserved in the mouse and correspond to $D_{5}, D_{162}$ and $D_{175} .{ }^{4}$ This suggests the existence of a linker peptide between the large and small subunits as is the case with human caspase-6 (ranging from $D_{162}$ to $D_{175}$ ).

Procaspase-7 was fully processed by caspase-6, -1, -11 and -3 (Figure 4C). Caspase-8 also generated efficiently $\sim$ p20 and $\sim$ p10 fragments indicative of active caspase-7 (Figure 4C). On the other hand, caspase-7 potently autoprocessed between its short prodomain and the $\sim$ p20 subunit $\left(D_{G V D_{23}}\right) \cdot D_{23}$ and $D_{198}$ are conserved between human and murine caspase- $7^{4}$ and have been reported as the caspase cleavage sites in human caspase$7 .^{15}$ The origin of the $17-\mathrm{kDa}$ fragment obtained with caspase- 1 is unclear.

\section{Ordering of caspases on the basis of their enzymatic specificity}

The following conclusions can be drawn from the in vitro cleavage data of procaspases by mature caspase-1, -2, -3, -6, $-7,-8$ or -11 (Figure 5):

\begin{tabular}{|c|c|c|c|c|c|c|c|}
\hline \multirow{2}{*}{ SUBSTRATES } & \multicolumn{2}{|c|}{$\begin{array}{l}\text { proinflammatory } \\
\text { caspases }\end{array}$} & \multicolumn{2}{|c|}{$\begin{array}{l}\text { receptor-associated } \\
\text { caspases }\end{array}$} & \multicolumn{3}{|c|}{ effector caspases } \\
\hline & CASP-1 & CASP-11 & CASP-2 & CASP-8 & CASP-3 & CASP-6 & CASP-7 \\
\hline \begin{tabular}{|l|} 
pro-CASP-1 \\
\end{tabular} & $\Delta$ & $\Delta$ & & $\Delta \Delta \Delta \Delta$ & & & \\
\hline pro-CASP-11 & 0 & & & $\Delta \Delta$ & & & \\
\hline pro-CASP-12 & & & & 0002 & 0 & & 0 \\
\hline \begin{tabular}{|l|} 
pro-CASP-2 \\
\end{tabular} & $\Delta$ & $\Delta$ & $\Delta \Delta \Delta$ & 0000 & $\Delta \bullet 00$ & $\Delta \Delta$ & $\Delta \bullet$ \\
\hline & & & & & & & \\
\hline pro-CASP-3 & $\Delta \Delta \Delta$ & 800 & & 0000 & 00 & 0 & 0 \\
\hline \begin{tabular}{|l|} 
pro-CASP-6-6 \\
pro-CASP-7
\end{tabular} & 00 & 00 & & \begin{tabular}{|l}
000 \\
0909
\end{tabular} & $\infty$ & 000 & $\frac{100}{000}$ \\
\hline \begin{tabular}{|l} 
pro-CASP-7 \\
pro-CASP-8
\end{tabular} & 0 & 0 & & $\Delta \Delta \Delta 00$ & $\Delta \Delta \bullet$ & $\Delta \Delta \bullet$ & $\begin{array}{l}000 \\
0\end{array}$ \\
\hline
\end{tabular}

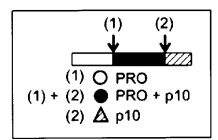

Figure 5 Overview of in vitro cleavage of procaspase substrates by caspases. Data are compiled from the results illustrated in Figures 2-4. The different cleavage patterns are represented by symbols according to the lower scheme; the relative strength of cleavage is indicated by the number of symbols. Caspase-12 was not included as an enzyme since no substrate has been identified so far (i) All mature caspases tested processed their own precursor form, except for caspase-11. This processing does not always result in full caspase maturation. For example, caspase-1 and caspase-2 processed between their $\sim$ p20 and $\sim$ p10 subunits, but caspase-7 mainly processed its own precursor form at the short prodomain. On the other hand, the active forms of caspase-8, caspase- 6 and caspase- 3 were able to fully process their own precursor form, suggesting a powerful proteolytic autoamplification. Moreover, since the $\sim$ p36/ $\sim$ p10 forms of both caspase- 1 and -4 have been demonstrated to be enzymatically active, ${ }^{8}$ cleavages at the link between $\sim$ p20 and $\sim$ p10 subunits may be sufficient to activate also other caspases. Taking this type of cleavage as a parameter for activation of the respective caspases, our data suggest that also caspase-2 is capable of activating its precursors.

(ii) The apical caspase- 8 was able to process all procaspases tested. Procaspase-2 and the effector procaspases- $3,-6$ and -7 were very efficiently and fully maturated, while caspase-8 was also the most efficient caspase in processing proinflammatory caspases. The preferred cleavage of procaspase-1 and -11 by caspase-8 took place at the boundary of the $\sim$ p20 and $\sim$ p10 subunits. As mentioned above, this type of cleavage presumably activates caspase-1 and -11 . Procaspase-12 was very efficiently cleaved by caspase- 8 between the prodomain and the $\sim$ p20 subunit (proteolysis between $\sim$ p20 and $\sim$ p10 was much weaker).

(iii) Caspase-1 and -11 processed procaspase-3 and procaspase-7, and to some degree also procaspase-6, but not vice versa. This imposes a hierarchical order in the procaspase activation cascade leading from proinflammatory to effector caspases. Interestingly, caspase1 and caspase-11 did not process procaspase-8, placing these caspases downstream of caspase-8 or in a completely separate activation pathway.

(iv) The couples caspase- 3 and caspase-6, caspase- 6 and caspase-7, or caspase- 3 and caspase- 8 maturate each other's precursors well, providing potential intermolecular proteolytic amplification.

(v) Our data also suggest the existence of positive feedback loops that make use of multiple caspases.

(vi) The only activity detected for caspase-2 is processing of its own precursor. Procaspase- 2 was strongly activated by caspase- 3 and -8 , and to a lesser extent by caspase-7. This indicates that caspase-2 may be involved in a caspase cascade, but cannot initiate a wide procaspase activation cascade by itself, at least not with the procaspases examined.

\section{Discussion}

We here report on the in vitro mutual processing of eight murine caspases (caspase-1, -2, -3, -6, -7, -8, -11/4 and -12) in order to gain insight into possible caspase proteolytic cascades. Unfortunately, we were not able to show enzymatic activity of caspase-12, not even upon separate expression of the $\sim$ p20 and $\sim$ p10 subunits in bacteria and subsequent 
mixing of both fragments; possibly a suitable substrate has not yet been identified. All other caspases exhibited proteolytic activity to a different extent on at least one of the oligopeptide substrates tested. This variation in specific enzymatic activity is most probably due to substrate specificity of the caspases.

Caspase-1 and -11 are able to maturate the effector procaspases-3 and -6 . Hence, the proinflammatory caspases can act upstream of the effector caspases. Remarkably, none of the effector proteases caspase-3, -6 or -7 could proteolyze the proinflammatory procaspase- 1 or -11 . These results are in agreement with reports on sequential activation of caspase-1-like and caspase-3-like proteases in the course of Fas-mediated apoptosis. ${ }^{18,37}$

The effector caspases procaspase- $3,-6$ and -7 were very efficiently activated by caspase-8. Additionally, among all caspases examined, caspase-8 was the best enzyme for in vitro processing of the proinflammatory procaspases-1, 11 and -12 . Since caspase- 1 and -11 are also efficient activators of the effector caspases, it might be hypothesized that, depending on the cell line and/or the apoptotic stimulus, the inflammatory caspases might be involved in the amplification of caspase-8-initiated activation of effector caspases. A few cell types (thymocytes and embryonic fibroblasts) of caspase-1 and -11 knockout mice exhibit reduced Fas-mediated cell death, ${ }^{27,38,39}$ which suggests that caspase- 8 might at least partially act by activating proinflammatory caspases. So the death pathway may need caspase-1 and/or -11 in some cell types for its proper execution, while in other cell types these caspases are not included or can be by-passed.

Interestingly, not only caspase-8 itself, but also caspase3 was able to fully process procaspase- 8 in vitro. In addition, caspase- 6 was able to process procaspase-8 substantially at the $\sim$ p20/ $\sim$ p10 subunit border generating a $43-\mathrm{kDa}$ and an $11-\mathrm{kDa}$ fragment. The latter cleavage is a first step in the activation process of procaspase- 8 by active caspase-8. ${ }^{31}$ This suggests that maturation of procaspase-8 may not only result from oligomerization-induced autocatalysis, ${ }^{10-12}$ but may in some systems also result from proteolytic cleavage by caspase- 3 or -6 . Consequently, caspase- 3 and -6 may constitute a positive feedback mechanism potentiating procaspase-8 activation at either the receptor site or at other subcellular localizations.

As already discussed above, caspase-1 and caspase-11 unidirectionally activate procaspase-3 and -7. Caspase-3 and -7 in turn efficiently maturate procaspase- 6 . Because of the weak ability of caspase-1 and -11 to process procaspase- 6 , the latter most likely becomes activated by caspase- 3 and -7 . Caspase- 6 in turn is a very potent processor of procaspase-3 and -7, providing a positive feedback system to both of them. There is no such mutual proteolytic amplification between caspase-3 and caspase-7.

Our data also suggest that the intracellular proteolytic caspase-signaling pathways operate in a network-like fashion, in which initial activation of one caspase can lead to activation of multiple other family members, resulting in cleavage of many different substrates. A remarkable observation, however, it that a similar set of cellular events is induced, irrespective of the apoptotic stimulus, such as tumor necrosis factor-ligand family members, growth factor depletion, drugs, irradiation, or viral infection. This implies that apoptosis induction finally converges at the same set of effector caspases. The procaspase activation network, as proposed here, might integrate the different apoptotic stimuli to an identical proteolytic output. One should be aware that the cellular context is more complex than a mixture of labeled procaspases and recombinant caspases as used here. In the present study, the activity of the crucial caspase- 9 is not included. ${ }^{22}$ Nevertheless, most fragmentary in vitro and in vivo studies on mutual procaspase activation schemes reported in the literature do fit in the network model presented here.

\section{Materials and Methods}

\section{Bacterial expression of murine caspase-x $(x=1,2,3,6,7,8,11$ or 12$)$}

Full-length cDNA clones of murine caspases ${ }^{4}$ were used as a template for PCR amplification with Vent-DNA polymerase (New England Biolabs, Beverly, MA, USA) to generate p30 caspases (sometimes referred to as $\Delta$ procaspases). First, a p30 caspase- 1 construct was made using synthetic oligonucleotide primers designed to eliminate the N-terminal region corresponding to the prodomain of caspase-1, to add an EcoRV restriction site upstream of an inserted Met start codon and to append a 10 amino acid (N)SAWRHPQFGG(C) Strep tag to the C-terminus of caspase- $1,{ }^{40}$ followed by two stop codons as well as BamHI, Munl, EcoRI and Xbal restriction sites. GCGGATATCGGTACCTGCCACCATGGGCACATTTCCAGGACTGACTGG was used as sense primer. The antisense primer, including the Strep tag, was CGCGTCTAGAGAATTCAATTGCCGGATCCTATTAACCACCAAACTGGGGGTGGCGCCAAGCGCTAGCATGTCCCGGGAAGAGGTAGAAACGT. The resulting PCR product was digested with $E c o R V$ and EcoRI, and was inserted into an Ehel/EcoRl-opened pLT10TH plasmid ${ }^{41}$ downstream of the $\mathrm{His}_{6}$ tag, to generate pLTmCASP-1a. This plasmid was further used as a basic vector to subclone other caspases. The primers CGGGGTACCTGCCACC A T G G A T C TGGGATCTATCTGGACAGTAG and CGCGCTAGCGTGATAAAAGTACAGTTCTTTCGT were used for p30 caspase-3 amplification. The p30 caspase- 6 amplicon was generated with the primers CGGGGTACCTGCCACCATGGCACCAGCCGAGCAGTACAAGATGGA and CGGGCTAGCCTTGCTAGGTTTGGGACAGAAATG. For the p30 caspase-11 amplicon, the primers CGGGGTACCTGCCACCATGGCACCAGGCAGCCACCATGGTGAAGC and CGCGCTAGCGTTGCCAGGAAAGAGGTAGAAATA were used, while p30 caspase-12 was obtained with the primers CGGGGTACCTGCCACCATGGAAATGGAGGTAAATGCTGGATTGG and CGGGCTAGCATTCCCGGGAAAAAGGTAGAAATA. The resulting DNA fragments were Kpnl/Nhel-cloned in pLTmCASP$1 \mathrm{a}$, replacing the caspase- 1 reading frame, to generate $\mathrm{pLTmCASP}-\mathrm{x}$ $(x=3,6,11$ or 12$)$. p30 caspase-7 and p30 caspase-2 were Ncol/Nhelcloned in a slightly different pLTmcaspase-1 plasmid, which contained an in-frame $\mathrm{Ncol}$ restriction site instead of a Kpnl site, and which was named pLTmCASP-1b. p30 caspase-7 was amplified with the primers CGGGGTACCACCATGGCCAAGCCAGACCGCTCCTCTATC and CGGGCTAGCACGGCTGAAGTACAGCTCTTTGGT. The primers CGGGGTACCACCATGGCAACAAGTCTCCCTTTCTCGGTGTGT and CGCGCTAGCCGTGGGTGGGTAGCCTGGGAACAG were used for p30 caspase-2. The plasmids generated were named pLTmCASP7 and -2 , respectively. The primers GCGGATATCCAGTGAGTCACGGACTTCAGACAAAG and GCGGATATCGAATTCTCATTAGGGAGG- 
GAAGAAGAGCTTC were used to generate pLTmCASP-8. EST clone 533745 (Washington University School of Medicine, St. Louis, MO, $\mathrm{USA}^{42}$ ) was used as template DNA; the amplicon was EcoRV-cloned into pLT10TH. As a result, murine caspase-8 did not contain a Strep tag. All plasmid inserts were confirmed by dideoxy-DNA sequencing and transformed in MC1061 bacteria containing a pICA2 plasmid (N Mertens, unpublished data). Exponentially growing $E$. coli bacteria $\left(A_{600}=0.5\right)$ were induced overnight with $1 \mathrm{mM}$ isopropyl $\beta$-Dthiogalactopyranoside at $20^{\circ} \mathrm{C}$. The cells were harvested by centrifugation and the cell paste was frozen until required. Frozen MC1061 cell pellets were suspended in buffer A, comprising $20 \mathrm{mM}$ Tris- $\mathrm{HCl}, \mathrm{pH} 7.5,10 \%$ glycerol, $1 \mathrm{mM}$ oxidized glutathione, $200 \mathrm{mM}$ $\mathrm{NaCl}, 1 \mathrm{mM}$ phenylmethylsulfonyl fluoride, $50 \mu \mathrm{M}$ leupeptin and $20 \mu \mathrm{g} /$ $\mathrm{ml}$ aprotinin (approximately $28 A_{600} / \mathrm{ml}$ ), and were lysed by sonication or in a French press. Insoluble proteins were removed by centrifugation. Bacterial DNA was removed over a DEAE column (XK26/20) (Pharmacia Biotech, Uppsala, Sweden) equilibrated with buffer $\mathrm{A}$. The flow-through was applied on a $\mathrm{Co}^{+2}$ metal chelate column (Clontech Laboratories, Palo Alto, CA, USA), which was washed with buffer $A$ for 4 to $16 \mathrm{~h}$. Low-strength metal-binding proteins were removed by a short washing with buffer $\mathrm{B}$, consisting of $20 \mathrm{mM}$ Tris- $\mathrm{HCl} \mathrm{pH} \mathrm{7.5,} \mathrm{10 \%} \mathrm{glycerol,} 1 \mathrm{mM}$ oxidized glutathione, $200 \mathrm{mM}$ $\mathrm{NaCl}$ and $10 \mathrm{mM}$ imidazole. $\mathrm{His}_{6}$-tagged caspase was eluted from the column with buffer $\mathrm{C}$, containing $20 \mathrm{mM}$ Tris- $\mathrm{HCl} \mathrm{pH} \mathrm{7.5,10 \%} \mathrm{glycerol,}$ $1 \mathrm{mM}$ oxidized glutathione, $50 \mathrm{mM} \mathrm{NaCl}$ and $100 \mathrm{mM}$ imidazole. The purity of the preparation was checked by SDS-PAGE. Only murine caspase-7 was purified to homogeneity at this stage. Caspase-1, - 2, -3 and -12 were further purified over Q-Resource (Pharmacia Biotech) whereas caspase-6, -8 and -11 were purified over monoQ columns (Pharmacia Biotech). p30 caspases were processed in the bacteria with variable efficiency to the $\sim$ p20 and $\sim$ p10 subunits characteristic of active caspase. To estimate the amount of $\sim$ p20 subunit, a dilution series of purified caspases and of a reference protein (purified lysozyme; Sigma-Aldrich, Deisenhoven, FRG) was made. The different subunits of the caspases were separated on $15 \%$ SDS PAGE, together with the reference protein, and were visualized with Coomassie blue. Scanning of the gels allowed approximate quantification of the $\sim$ p20 subunit with the concentration of the reference protein as internal standard and by means of ImageQuant software (Phosphorlmager; Molecular Dynamics, Sunnyvale, CA, USA) (data not shown).

\section{Assays on synthetic substrates}

Activity assays on peptide substrates were performed in a reaction buffer containing $220 \mathrm{mM}$ mannitol, $170 \mathrm{mM}$ sucrose, $5 \mathrm{mM} \mathrm{NaCl}$, $5 \mathrm{mM} \mathrm{MgCl}_{2}, 10 \mathrm{mM}$ HEPES pH 7.5 and $2.5 \mathrm{mM} \mathrm{KH}_{2} \mathrm{PO}_{4}$. Purified murine caspases containing $60 \mathrm{ng}$ of $\sim$ p20 subunit were diluted with reaction buffer. The peptides Ac-YVAD-amc and Ac-DEVD-amc (Peptide Institute, Osaka, Japan) or custom-synthesized zVAD-afc (Enzyme Systems, Dublin, CA, USA) were added to a final concentration of $50 \mu \mathrm{M}$. The total volume was adjusted to $150 \mu \mathrm{l}$. The generation of free 7-amino-4-methylcoumarin (amc) was continuously monitored for $30 \mathrm{~min}$ in a fluorometer (CytoFluor; PerSeptive Biosystems, Framingham, MA, USA) at an excitation wavelength of $360 \mathrm{~nm}$ and an emission wavelength of $460 \mathrm{~nm}$. Free 7amino-4-trifluoromethylcoumarin (afc) was monitored at an excitation wavelength of $409 \mathrm{~nm}$ and an emission wavelength of $505 \mathrm{~nm}$. One unit of purified caspase represents the amount of enzyme necessary to generate 1 pmole of free amc or afc/min from $50 \mu \mathrm{M}$ peptide substrate at $30^{\circ} \mathrm{C}$.

\section{In vitro transcription/translation}

The inserts, encoding the entire open reading frame, used to obtain pCAGGS-mCASP- $x^{4}$ were cloned into a pGEM11zf(+) vector (Promega, Madison, WI, USA). The resulting plasmids were named pGEM-mCASP-x $(x=1,2,3,6,7,11$ or 12). Full-length murine caspase-8 was cloned into a pCDNA3 vector (Invitrogen, San Diego, CA, USA) to generate pCDNA-mCASP-8. All these plasmids were used to produce radiolabeled murine precursor caspases by coupled transcription/translation (TNT kit; Promega) according to the manufacturer's recommendations. To produce ${ }^{35} \mathrm{~S}$-Met-labeled prodomain-deleted caspases, pLTmCASP-x plasmids were used (data not shown). The reaction products were analyzed by SDSPAGE and stored at $-70^{\circ} \mathrm{C}$ until needed.

\section{In vitro assay of active $\mathrm{p} 30$ caspases on labeled substrates}

The equivalent of $60 \mathrm{ng}$ of $\sim$ p20 subunit of purified caspase was incubated with $1 \mu \mathrm{l}$ of in vitro radiolabeled substrate in a total volume of $25 \mu$ l caspase buffer (50 mM HEPES pH 7.5, $10 \mathrm{mM}$ dithiothreitol, $1 \mathrm{mM}$ EDTA, $1 \mathrm{mM}$ phenylmethylsulfonyl fluoride, $50 \mu \mathrm{M}$ leupeptin and $20 \mu \mathrm{g} / \mathrm{ml}$ aprotinin) for $1.5 \mathrm{~h}$ at $37^{\circ} \mathrm{C}$. The resulting cleavage products were analyzed on $15 \%$ SDS-PAGE.

\section{Acknowledgements}

Research was supported by the Interuniversitaire Attractiepolen, the Centrum voor Studie en Behandeling van Gezwelziekten, an EC Biomed Program grant No. BMH4-CT96-0300 and a grant No. $9005097 \mathrm{~N}$ of the Fonds voor Wetenschappelijk Onderzoek-Vlaanderen. P Vandenabeele is a Research Associate with the Fonds voor Wetenschappelijk Onderzoek-Vlaanderen. The authors thank F Molemans and R Cocquyt for sequencing.

\section{References}

1. Thompson CB (1995) Apoptosis in the pathogenesis and treatment of disease. Science 267: 1456- 1462

2. Cohen GM (1997) Caspases: The executioners of apoptosis. Biochem. J. 326: $1-16$

3. Porter AG, NgP and Jänicke RU (1997) Death substrates come alive. BioEssays 19: $501-507$

4. Van de Craen M, Vandenabeele P, Declercq W, Van den brande I, Van Loo G, Molemans F, Schotte P, Van Criekinge W, Beyaert R and Fiers W (1997) Characterization of seven murine caspase family members. FEBS Lett. 403: 61-69

5. Van de Craen M, Van Loo G, Pype S, Van Criekinge W, Van den brande I, Molemans F, Fiers W, Declercq W and Vandenabeele P (1998) Identification of a new caspase homologue: Caspase-14. Cell Death Differ. 5: 838-846

6. Humke EW, Ni J and Dixit VM (1998) ERICE, a novel FLICE-activatable caspase. J. Biol. Chem. 273: 15702-15707

7. Van de Craen M, Van den brande I, Declercq W, Irmler M, Beyaert R, Tschopp J, Fiers W and Vandenabeele P (1997) Cleavage of caspase family members by granzyme B: A comparative study in vitro. Eur. J. Immunol. 27: 1296-1299

8. Yamin T-T, Ayala JM and Miller DK (1996) Activation of the native 45-kDa precursor form of interleukin-1-converting enzyme. J. Biol. Chem. 271: 1327313282

9. Van Criekinge W, Beyaert R, Van de Craen M, Vandenabeele P, Schotte P, De Valck D and Fiers W (1996) Functional characterization of the prodomain of interleukin-1 $\beta$-converting enzyme. J. Biol. Chem. 271: 27245-27248 
10. Martin DA, Siegel RM, Zheng L and Lenardo MJ (1998) Membrane oligomerization and cleavage activate the caspase-8 (FLICE/MACH $\alpha 1$ ) death signal. J. Biol. Chem. 273: 4345-4349

11. Muzio M, Stockwell BR, Stennicke HR, Salvesen GS and Dixit VM (1998) An induced proximity model for caspase-8 activation. J. Biol. Chem. 273: 29262930

12. Yang X, Chang HY and Baltimore D (1998) Autoproteolytic activation of procaspases by oligomerization. Mol. Cell 1:319-325

13. Howard AD, Kostura MJ, Thornberry N, Ding GJ-F, Limjuco G, Weidner J, Salley JP, Hogquist KA, Chaplin DD, Mumford RA, Schmidt JA and Tocci MJ (1991) IL$1 \beta$-converting enzyme requires aspartic acid residues for processing of the $\mathrm{IL}-1 \beta$ precursor at two distinct sites and does not cleave 31-kDa IL-1 $\alpha$. J. Immunol. 147 2964-2969

14. Darmon AJ, Nicholson DW and Bleackley RC (1995) Activation of the apoptotic protease CPP32 by cytotoxic T-cell-derived granzyme B. Nature 377: 446-448

15. Fernandes-Alnemri T, Armstrong RC, Krebs J, Srinivasula SM, Wang L, Bullrich F, Fritz LC, Trapani JA, Tomaselli KJ, Litwack G and Alnemri ES (1996) in vitro activation of CPP32 and Mch3 by Mch4, a novel human apoptotic cysteine protease containing two FADD-like domains. Proc. Natl. Acad. Sci. USA 93 7464-7469

16. Schotte P, Van Criekinge W, Van de Craen M, Van Loo G, Desmedt M, Grooten J Cornelissen M, De Ridder L, Vandekerckhove J, Fiers W, Vandenabeele P and Beyaert R (1998) Cathepsin B-mediated activation of the proinflammatory caspase-11. Biochem. Biophys. Res. Commun. 251: 379-387

17. Vancompernolle K, Van Herreweghe F, Pynaert G, Van de Craen M, De Vos K Totty N, Sterling A, Fiers W, Vandenabeele P and Grooten J (1998) Atractylosideinduced release of cathepsin $B$, a protease with caspase-processing activity. FEBS Lett. 438: $150-158$

18. Enari M, Talanian RV, Wong WW and Nagata S (1996) Sequential activation of ICE-like and CPP32-like proteases during Fas-mediated apoptosis. Nature 380: $723-726$

19. Orth K, O'Rourke K, Salvesen GS and Dixit VM (1996) Molecular ordering of apoptotic mammalian CED-3/ICE-like proteases. J. Biol. Chem. 271: $20977-$ 20980

20. Srinivasula SM, Ahmad M, Fernandes-Alnemri T, Litwack $G$ and Alnemri ES (1996) Molecular ordering of the Fas-apoptotic pathway: The Fas/APO-1 protease Mch5 is a CrmA-inhibitable protease that activates multiple Ced-3/ICElike cysteine proteases. Proc. Natl. Acad. Sci. USA 93: 14486-14491

21. Hirata H, Takahashi A, Kobayashi S, Yonehara S, Sawai H, Okazaki T, Yamamoto K and Sasada M (1998) Caspases are activated in a branched protease cascade and control distinct downstream processes in Fas-induced apoptosis. J. Exp. Med. 187: 587-600

22. Slee EA, Harte MT, Kluck RM, WolfBB, Casiano CA, Newmeyer DD, Wang H-G, Reed JC, Nicholson DW, Alnemri ES, Green DR and Martin SJ (1999) Ordering the cytochrome $c$-initiated caspase cascade: Hierarchical activation of caspases-2, -3, -6, -7, -8, and -10 in a caspase-9-dependent manner. J. Cell Biol. 144: $281-292$

23. Van de Craen M, Van Loo G, Declercq W, Schotte P, Van den brande I, Mandruzzato S, van der Bruggen P, Fiers W and Vandenabeele P (1998) Molecular cloning and identification of murine caspase-8. J. Mol. Biol. 284: 1017-1026

24. Thornberry NA, Rano TA, Peterson EP, Rasper DM, Timkey T, Garcia-Calvo M, Houtzager VM, Nordstrom PA, Roy S, Vaillancourt JP, Chapman KT and Nicholson DW (1997) A combinatorial approach defines specificities of members of the caspase family and granzyme B. Functional relationships established for key mediators of apoptosis. J. Biol. Chem. 272: 17907-17911

25. Stennicke HR, Jurgensmeier JM, Shin H, Deveraux Q, WolfBB, Yang X, Zhou Q, Ellerby HM, Ellerby LM, Bredesen D, Green DR, Reed JC, Froelich CJ and Salvesen GS (1998) Pro-caspase-3 is a major physiologic target of caspase-8. J. Biol. Chem. 273: 27084-27090
26. Muzio M, Salvesen GS and Dixit VM (1997) FLICE induced apoptosis in a cellfree system. Cleavage of caspase zymogens. J. Biol. Chem. 272: 2952-2956

27. Wang S, Miura M, Jung Y, Zhu H, Li E and Yuan J (1998) Murine caspase-11, an ICE-interacting protease, is essential for the activation of ICE. Cell 92: 501-509

28. Chin YE, Kitagawa M, Kuida K, Flavell RA and Fu X-Y (1997) Activation of the STAT signaling pathway can cause expression of caspase 1 and apoptosis. Mol. Cell. Biol. 17: $5328-5337$

29. LiH, Bergeron L, Cryns V, Pasternack MS, Zhu H, Shi L, Greenberg A and Yuan J (1997) Activation of caspase-2 in apoptosis. J. Biol. Chem. 272: 21010-21017

30. Butt AJ, Harvey NL, Parasivam G and Kumar S (1998) Dimerization and autoprocessing of the Nedd2 (caspase-2) precursor requires both the prodomain and the carboxy-terminal regions. J. Biol. Chem. 273: 6763-6768

31. Medema JP, Scaffidi C, Kischkel FC, Shevchenko A, Mann M, Krammer PH and Peter ME (1997) FLICE is activated by association with the CD95 death-inducing signaling complex (DISC). EMBO J. 16: 2794-2804

32. Muzio M, Chinnaiyan AM, Kischkel FC, O'Rourke K, Shevchenko A, Ni J, Scaffidi C, Bretz JD, Zhang M, Gentz R, Mann M, Krammer PH, Peter ME and Dixit VM (1996) FLICE, a novel FADD homologous ICE/CED-3-like protease, is recruited to the CD95 (Fas/Apo-1) death-inducing signaling complex. Cell 85: 817-827

33. Han Z, Hendrickson EA, Bremner TA and Wyche JH (1997) A sequential twostep mechanism for the production of the mature $\mathrm{p} 17: \mathrm{p} 12$ form of caspase- 3 in vitro. J. Biol. Chem. 272: $13432-13436$

34. Tewari M, Quan LT, O'Rourke K, Desnoyers S, Zeng Z, Beidler DR, Poirier GG, Salvesen GS and Dixit VM (1995) Yama/CPP32 $\beta$, a mammalian homolog of CED-3, is a CrmA-inhibitable protease that cleaves the death substrate poly(ADP-ribose) polymerase. Cell 81: 801-809

35. Kang JJ, Schaber MD, Srinivasula SM, Alnemri ES, Litwack G, Hall DJ and Bjornsti M-A (1999) Cascades of mammalian caspase activation in the yeast Saccharomyces cerevisiae. J. Biol. Chem. 274: 3189-3198

36. Srinivasula SM, Fernandes-Alnemri T, Zangrilli J, Robertson N, Armstrong RC, Wang L, Trapani JA, Tomaselli KJ, Litwack G and Alnemri ES (1996) The Ced-3/ interleukin $1 \beta$ converting enzyme-like homolog Mch6 and the lamin-cleaving enzyme Mch2 $\alpha$ are substrates for the apoptotic mediator CPP32. J. Biol. Chem. 271: 27099-27106

37. Rouquet N, Carlier K, Briand P, Wiels J and Joulin V (1996) Multiple pathways of Fas-induced apoptosis in primary culture of hepatocytes. Biochem. Biophys. Res. Commun. 229: 27-35

38. Kuida K, Lippke JA, Ku G, Harding MW, Livingston DJ, Su MS-S and Flavell RA (1995) Altered cytokine export and apoptosis in mice deficient in interleukin-1 $\beta$ converting enzyme. Science 267: 2000-2003

39. Shi L, Chen G, MacDonald G, Bergeron L, Li H, Miura M, Rotello RJ, Miller DK, Li P, Seshadri T, Yuan J and Greenberg AH (1996) Activation of an interleukin 1 converting enzyme-dependent apoptosis pathway by granzyme B. Proc. Natl. Acad. Sci. USA 93: 11002-11007

40. Schmidt TGM and Skerra A (1994) One-step affinity purification of bacterially produced proteins by means of the 'Strep tag' and immobilized recombinant core streptavidin. J. Chromatogr. A. 676: 337-345

41. Mertens N, Remaut E and Fiers W (1995) Versatile, multi-featured plasmids for high-level expression of heterologous genes in Escherichia coli: Overproduction of human and murine cytokines. Gene 164: 9-15

42. Lennon G, Auffray C, Polymeropoulos M and Soares MB (1996) The I.M.A.G.E. Consortium: An integrated molecular analysis of genomes and their expression. Genomics 33: $151-152$

43. Görg A, Obermaier C, Boguth G, Csordas A, Dias JJ and Madjar JJ (1997) Very alkaline immobilized $\mathrm{pH}$ gradients for two-dimensional electrophoresis of ribosomal and nuclear proteins. Electrophoresis 18: 328-337 